Kibiti and Afolayan, Afr J Tradit Complement Altern Med., (2018) 15 (3): 38-46

https://doi.org/10.21010/ajtcam.v15i3.5

\title{
MINERAL COMPOSITION AND NUTRITIVE ANALYSIS OF BULBINE ABYSSINICA A. RICH. USED IN THE TREATMENT OF INFECTIONS AND COMPLICATIONS ASSOCIATED WITH DIABETES MELLITUS IN THE EASTERN CAPE PROVINCE, SOUTH AFRICA
}

\section{Cromwell Mwiti Kibiti, Anthony Jide Afolayan*}

Medicinal Plants and Economic Development (MPED) Research Centre, Department of Botany, University of Fort Hare, Alice, 5700, South Africa.

*Corresponding Author Email: aafolayan@ufh.ac.za

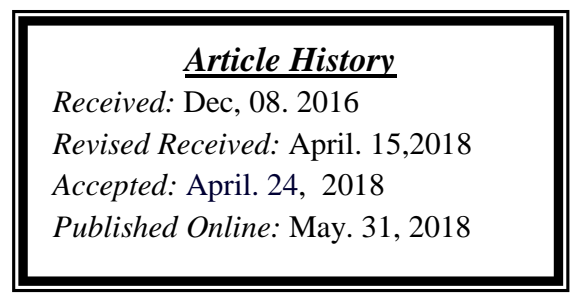

\begin{abstract}
Background: $B$. abyssinica is a succulent member of the genus Bulbine (Asphodelaceae). It occurs from the Eastern Cape, through Swaziland and further north to Ethiopia. The species is used in traditional medicine to treat rheumatism, dysentery, bilharzia, cracked lips and diabetes. The tea leaf is used to treat cough, vaginal and bladder problems. Whereas $B$. abyssinica has ethno medicinal value, not much data concerning its phytonutrient, macro and micro element composition can be found in literature.

Materials and Methods: Therefore, the present study was undertaken to determine the nutritional quantitative composition of the plant using standard procedures.

Results: The proximate analysis revealed the carbohydrate, crude fibre, moisture, ash, crude protein and crude fat contents as $74.8 \%, 8.9 \%, 8.8 \%, 8 \%, 7.7 \%$ and $0.6 \%$, respectively. The species showed high levels of oxalates and phytic acids, moderate levels of alkaloids, flavonoids, saponins and phenols, while tannins were in low levels. Vitamin A, C and E contents were $12,12.3$ and $22.1 \mathrm{mg} / 100 \mathrm{~g}$, respectively. Amongst the mineral elements investigated, potassium and calcium were in high levels. Magnesium, iron, sodium, aluminium and phosphorus were moderately present, while manganese, zinc and copper where in low amounts. These vitamins and mineral elements were within their recommended daily allowance in humans.

Conclusion: The amount of these phytochemicals suggests the plant can serve as nutritional supplements which are vital in maintaining good health status. These findings also suggest the potential role of $B$. abyssinica in the treatment of infections and some chronic diseases, especially diabetes mellitus.
\end{abstract}

Keywords: Bulbine abyssinica, proximate composition, vitamins, mineral elements

\section{Introduction}

Medicinal plants have contributed immensely to health care in Africa and are known to play important roles as source of food and maintenance of good health. These plants are assessable and cheap sources of important nutrients, macro and micro elements, vitamins, certain hormone precursors, protein, energy and essential amino acids (Marcel and Bievenu, 2012). These phytoconstituents have crucial nutritional importance in the prevention and treatment of chronic disease such as cancer, cardiovascular disease and diabetics (Marcel and Bievenu, 2012).

The genus Bulbine (Asphodelaceae) comprises about 40 species in South Africa. These plants are mostly herbs with leaves that are evergreen and succulent in appearance. They have thick fleshy tuberous roots and are easy to grow (Wanjohi et al., 2005). In traditional African medicine, various Bulbine species are used to treat a number of conditions including sexually transmitted diseases, wound infections, dysentery and urinary tract infections (Wanjohi et al., 2005). Bulbine species are commonly used by traditional healers in South Africa in the treatment of wounds, burns, rashes, itches, ringworm, cracked lips and herpes (Wanjohi et al., 2005). 
Bulbine abyssinica is a succulent, perennial herb with a rhizomatous base which grows in small clusters. The plant is a hardy, water-wise plant that offers a brilliant yellow display when in flower. Both flowers and fruit have an attractive bicolored (yellow and black) appearance. The roots are many, slender or swollen. It has soft, dark green leaves which are grass-like and up to $350 \mathrm{~mm}$ long. Mature fruits are black, $4 \mathrm{~mm}$ in diameter and often covered with the faded perianth persisting as a cap. B. abyssinica occurs from the Eastern Cape, through KwaZulu-Natal, Swaziland, Lesotho, Free State, North-West, Gauteng, Mpumalanga, Limpopo and further north to Ethiopia (Pooley, 1998).

B. abysinica is often used in traditional medicine to treat rheumatism, dysentery, bilharzia and cracked lips (Wanjohi et al., 2005). The root decoction is used in treatment of infertility and back pain. The leaf is used to prepare tea which is taken to treat cough, vaginal and bladder problems. In South Africa, the whole plant is used by traditional healers in the management of diabetes mellitus (Oyedemi et al., 2009).

There is limited literature on the chemical and nutritive composition of Bulbine species. The stem and root of Bulbine species are known to contain anthraquinones such as chrysophanol and knipholone which have anti-bacterial properties. Some anthraquinones have been isolated from the roots of B. abyssinica (Bezabih et al., 1997). From the fruits of B. abyssinica, three new dimeric anthracene derivatives namely; abyquinone $\mathrm{A}$, abyquinone $\mathrm{B}$ and abyquinone $\mathrm{C}$ have also been isolated. Anthraquinones, phenylanthraquinones and isofuranonaphthoquinones have been isolated from the roots, leaves and fruits of B. abyssinica. The phenylanthraquinone, bulbine-knipholone has been isolated from the roots. This compound showed in-vitro antiplasmodial activity and no cytotoxic effects on mammalian cells (Bringmann et al., 2002).

Though advances have been made to scientifically validate some of $B$. abyssinica's chemical structures and bioactivities, its proximate, phytochemical and mineral composition with their medicinal value remains obscure (Wanjohi et al., 2005). Therefore, the objective of this study was to examine the proximate, phytochemical, macro and micro mineral quantitative composition of the whole plant using standard procedures and to relate our findings to their possible functional role in dietary-medicinal uses.

\section{Materials and Methods Plant collection and Preparation}

The whole plant of $B$. abyssinica including; leaves, flowers, stems and roots were collected within the Nkonkobe Municipality of the Eastern Cape Province, South Africa and the voucher specimen (KibMed 2014/01) was deposited in the Giffen's herbarium, University of Fort Hare for authentication. The plant samples were properly washed, air dried, ground to fine powder and stored in airtight bottles which were then kept in the refrigerator at $4^{\circ} \mathrm{C}$ until needed for the analysis.

\section{Proximate analysis}

The moisture content was determined as described by A.O.A.C (2005). Briefly, a clean crucible was dried to a constant weight in air oven at $110^{\circ} \mathrm{C}$, cooled in a desiccator and Weighed (W1). Two grams of finely ground sample was accurately weighed into the previously labeled crucible and reweighed (W2). The crucible containing the sample was dried in an oven to constant Weight (W3). The percentage (\%) moisture content was calculated as:

Moisture content $(\%)=($ final weight of the sample after incineration $(\mathrm{g}) /$ weight of initial sample $(\mathrm{g}) \times 100$.

The ash content of the plant was determined using the method of Antia et al., (2006). Briefly, $5 \mathrm{~g}$ of the powdered sample was incinerated in an E-Range muffle furnace with TOHO P4 programme at $550^{\circ} \mathrm{C}$ for $12 \mathrm{~h}$. The final weight of the sample was used to calculate the ash content as follows:

Ash content $(\%)=($ final weight of the sample after incineration $(\mathrm{g}) / 5 \mathrm{~g}) \times 100$.

Crude fat was determined as described by Antia et al. (2006). About $5 \mathrm{~g}$ of the powdered sample was weighed; $100 \mathrm{ml}$ of diethyl ether was added, covered with aluminium foil and shaken in an orbital shaker for $24 \mathrm{~h}$. It was then filtered and the supernatant decanted. Another $100 \mathrm{ml}$ of diethyl ether was added to the residue and shaken for another $24 \mathrm{~h}$. The residue obtained after filtration was the fat free sample and it was as calculated as follows:

Crude fat $=$ Weight of sample after diethyl ether extraction / Initial weight of sample $\mathrm{x} 100$.

The crude fibre content of the plant was determined also by the method of Antia et al. (2006). Briefly, $5 \mathrm{~g}$ of the powdered sample was weighed and digested in $100 \mathrm{ml}$ of $1.25 \%$ sulphuric acid for $30 \mathrm{~min}$. The acid digested sample was allowed to cool, and then filtered. The residue was collected for further digestion with $100 \mathrm{ml}$ of $1.25 \%$ sodium hydroxide. The sample was then filtered and the residue dried in an oven at $100^{\circ} \mathrm{C}$ to a constant weight. The dried residue was incinerated in a muffle furnace for $24 \mathrm{~h}$ at $550^{\circ} \mathrm{C}$. The crude fibre was obtained from the loss in weight on ignition of dried residue remaining after digestion of fat free samples as:

$\%$ fibre $=$ Loss of weight on ignition /Weight of sample used $\mathrm{x} 100$. 
The nitrogen content of the plant was determined using the method of Bvenura and Afolayan, (2012) by means of the Inductively Coupled Plasma -Optical Emission Spectrometer (ICP-OES). The value of nitrogen obtained was multiplied by 6.25 to give the $\%$ crude protein.

The carbohydrate content was determined by subtracting the total crude protein, crude fibre, ash and lipid from the total dry matter. The caloric value estimation was done by summing the multiplied values for crude protein, crude lipid (excluding crude fibre) and carbohydrate, respectively at Atwater factors (17 kJ, $37 \mathrm{~kJ}$ and $17 \mathrm{~kJ})(\mathrm{Moses}$ and Yemisi, 2010).

The percentage contribution to energy due to protein (PEP), due to total fat (PEF) and due to carbohydrate (PEC) as PEP\%, PEF\% and PEC\% respectively were calculated. The percentage utilizable energy due to protein (UEDP\%) was also calculated according to the method of Adeyeye (2014). All the analysis was done in triplicate.

\section{Phytochemical analysis}

Oxalate was determined by using the method of Naik et al. (2014). Briefly, $1 \mathrm{~g}$ of the sample was placed in $250 \mathrm{ml}$ volumetric flask, $190 \mathrm{ml}$ of distilled water and $10 \mathrm{ml}$ of $6 \mathrm{M}$ hydrochloric acid were added. The mixture was then warmed in a water bath at $90^{\circ} \mathrm{C}$ for $4 \mathrm{~h}$ and the digested sample centrifuged at 2,000 rpm for $5 \mathrm{~min}$. The supernatant was then diluted to $250 \mathrm{ml}$. Three $50 \mathrm{ml}$ aliquots of the supernatant was evaporated to $25 \mathrm{ml}$, the brown precipitate was filtered and washed. The combined solution was then titrated with concentrated ammonia solution in drops until the pink colour of methyl orange changed to yellow. The solution was then heated in a water bath to $90^{\circ} \mathrm{C}$ and the oxalate was precipitated with $5 \%$ calcium chloride solution which was allowed to stand overnight. This was centrifuged; the precipitate washed with hot $25 \%$ sulfuric acid, diluted to $125 \mathrm{ml}$ with distilled water and titrated against $0.05 \mathrm{M}$ potassium permanganate $\left(\mathrm{KMnO}_{4}\right)$. Oxalate content was calculated using the formula;

$1 \mathrm{ml} 0.05 \mathrm{M} \mathrm{KMnO}_{4}=2.2 \mathrm{mg}$ Oxalate

Phytic acid was determined by the method of Naik et al. (2014). Briefly, $2 \mathrm{~g}$ of the sample was weighed into a $250 \mathrm{ml}$ conical flask, soaked in $100 \mathrm{ml}$ of $2 \%$ concentrated hydrochloric acid for $3 \mathrm{~h}$ and then filtered with a Whatman No. 1 filter paper. To the $50 \mathrm{ml}$ of the filtrate, $10 \mathrm{ml}$ of distilled water were added to give proper acidity. Then, to this solution, $10 \mathrm{ml}$ of $0.3 \%$ ammonium thiocyanate solution was added and titrated with standard Iron (II) Chloride solution containing $0.00195 \mathrm{~g}$ Iron $/ \mathrm{ml}$, end point observed to be yellow which persisted for $5 \mathrm{~min}$. The percentage phytic acid was calculated thus:

$\%$ Phytic acid $=\mathrm{y} \times 1.19 \times 100 ;$ Where $\mathrm{y}=$ titre value $\times 0.00195 \mathrm{~g}$

Tannin determination was done according to the method of Wintola and Afolayan (2011), with some modifications. Briefly, to $0.2 \mathrm{~g}$ of the sample, $20 \mathrm{ml}$ of $50 \%$ methanol was added. This was shaken thoroughly and placed in a water bath at $80^{\circ} \mathrm{C}$ for $1 \mathrm{~h}$ to ensure uniform mixing. The extract was filtered into a $100 \mathrm{ml}$ volumetric flask, followed by the addition of $20 \mathrm{ml}$ of distilled water, $2.5 \mathrm{ml}$ of Folin-Denis reagent and $10 \mathrm{ml}$ of $17 \%$ sodium carbonate and was thoroughly mixed. The mixture was made up to $100 \mathrm{ml}$ with distilled water, mixed and allowed to stand for 20 min. The bluish-green color developed at the end of the reaction mixture of different concentrations ranges from 0 to 10 ppm. The absorbance of the tannic acid standard solutions as well as sample was measured after color development at $760 \mathrm{~nm}$ using the AJI-C03 UVVIS spectrophotometer. Results were expressed as $\mathrm{mg} / \mathrm{g}$ of tannic acid equivalent using the calibration curve:

$Y=0.0763 x, \mathrm{R}^{2}=0.9644$, where $x$ is the absorbance and $Y$ is the Tannic acid equivalent.

The amount of phenol in the whole plant extract of $B$. abyssinica was determined spectrophotometrically using the method of Wintola and Afolayan (2011), with Folin-Ciocalteu reagent. Briefly, an aliquot of the extract was mixed with 5 ml FolinCiocalteu reagent (previously diluted with water at a concentration of 1:10 v/v) and $4 \mathrm{ml}(75 \mathrm{~g} / \mathrm{l})$ of sodium carbonate. The tubes were vortexed for $15 \mathrm{sec}$ and left to stand for $30 \mathrm{~min}$ at $40^{\circ} \mathrm{C}$ for color development. Absorbance was then measured at $765 \mathrm{~nm}$ using the AJI-C03 UV-VIS spectrophotometer. Results were expressed as mg/g of gallic acid equivalent using the calibration curve:

$Y=0.121 x, R^{2}=0.936512$, where $x$ is the absorbance and $Y$ is the gallic acid equivalent.

Alkaloid determination was carried out following the procedure of Wintola and Afolayan (2011). Briefly, 5g of the sample was weighed into a $250 \mathrm{ml}$ beaker and $200 \mathrm{ml}$ of $10 \%$ acetic acid in ethanol was added and covered and allowed to stand for $4 \mathrm{~h}$. This was filtered and the extract was concentrated on a water bath to one quarter the original volume. Concentrated ammonium hydroxide was added drop wise to the extract until the precipitation was complete. The whole solution was allowed to settle, precipitate collected, washed with dilute ammonium hydroxide and then filtered. The residue is the alkaloid which was dried and weighed. The alkaloid content was determined using the formula:

$\%$ alkaloid $=$ final weight of the sample $/$ initial weight of the extract $\times 100$.

Quantitative determination of saponins was done using the method of Wintola and Afolayan (2011). Briefly, 20 g of the sample was added to $100 \mathrm{ml}$ of $20 \%$ aqueous ethanol and kept in a shaker for $30 \mathrm{~min}$. The samples were heated over a water bath for $4 \mathrm{~h}$ at $55^{\circ} \mathrm{C}$. The mixture was then filtered and the residue re-extracted with another $200 \mathrm{ml}$ of $20 \%$ aqueous ethanol. The combined extracts were reduced to approximately $40 \mathrm{ml}$ over the water bath at $90^{\circ} \mathrm{C}$. 
The concentrate was transferred into a $250 \mathrm{ml}$ separatory funnel and extracted twice with 20 ml diethyl ether. The ether layer was discarded while the aqueous layer was retained and to which $60 \mathrm{ml} n$-butanol was added. The $n$-butanol extracts were washed twice with $10 \mathrm{ml}$ of $5 \%$ aqueous sodium chloride. The remaining solution was heated on a water bath. After evaporation, the samples were dried in the oven at $40^{\circ} \mathrm{C}$ to a constant weight. The saponin content was calculated using the formula:

$\%$ saponin $=$ final weight of sample $/$ initial weight of extracts $\times 100$.

The method of Wintola and Afolayan (2011) was followed in the determination of flavonoid. Briefly, $5 \mathrm{~g}$ of the sample was extracted repeatedly with $100 \mathrm{ml}$ of $80 \%$ aqueous methanol at room temperature. The whole solution was filtered through whatman filter paper $(125 \mathrm{ml})$. The filtrate was later transferred into a crucible and evaporated into dryness and weighed to a constant weight.

$\%$ flavonoids $=$ final weight of the sample $/$ initial weight of the extract $\times 100$.

\section{Vitamin analysis}

The Vitamin C (Ascorbic acid) content of the plant was determined by a modified spectrophotometric method as described by Tahirovic et al. (2012). Briefly, $2.5 \mathrm{~g}$ of coarsely powdered sample was weighed and $12 \mathrm{ml}$ of glacial acetic acid added. The mixture was stirred for about $20 \mathrm{~min}$ and filtered. The filtered solution was made up to $100 \mathrm{ml}$ using distilled water. From this, $50 \mathrm{ml}$ of the sample solution was mixed with $10 \mu \mathrm{l}$ of methylene blue solution $(0.4 \mathrm{mmol} / \mathrm{l})$ and diluted to $10 \mathrm{ml}$ with distilled water. Absorption was measured at $665 \mathrm{~nm}$ using a spectrophotometer (AJ-IC03). Stock solution of ascorbic acid (1M) was prepared by dissolving $10 \mathrm{~g}$ of ascorbic acid in $56.76 \mathrm{ml}$ of distilled water. The different concentrations were prepared by diluting the stock standard solution in water before use and absorption was also measured at $665 \mathrm{~nm}$. The calibration graph was drawn by plotting the absorbance against concentration of ascorbic acid. The obtained calibration curve was linear in a concentration range of 0.1 to $1 \mathrm{M}$ with the linear regression equation as; $\mathrm{y}=0.0169 \mathrm{x}, \mathrm{R}^{2}=0.8208$, where $\mathrm{y}$ is the absorbance and $x$ is the concentration of Vit $\mathrm{C}$.

Quantitative determination of Vitamin A was done using the method of Onyesife et al. (2014). Briefly, $1 \mathrm{~g}$ of ground sample was macerated with $20 \mathrm{ml}$ of petroleum ether. This was decanted into a test tube and then evaporated to dryness. 0.2 $\mathrm{ml}$ of chloroform-acetic anhydride $(1: 1 \mathrm{v} / \mathrm{v})$ was added to the residue. A $2 \mathrm{ml}$ of Trichloroacetic acid-chloroform in like $(1: 1 \mathrm{v} / \mathrm{v})$ was added to the resulting solution and absorbance was measured at $620 \mathrm{~nm}$. Vitamin A standard was prepared in the same and the absorbance taken at $620 \mathrm{~nm}$. The concentration of vitamin A in the sample was extrapolated from the standard curve (Onyesife et al., 2014).

The Vitamin E content of the plant was determined using the method of Onyesife et al. (2014). Briefly, $1 \mathrm{~g}$ of the sample was macerated with $20 \mathrm{ml}$ of ethanol and then filtered. Then, $0.2 \%$ ferric chloride in ethanol and $1 \mathrm{ml}$ of $0.5 \% \alpha-\alpha-$ dipyridine was prepared and added to $1 \mathrm{ml}$ of the filtrate. This was diluted to $5 \mathrm{ml}$ with distilled water. Absorbance was taken at $520 \mathrm{~nm}$. The standard solutions were prepared similarly and the concentration of vitamin E extrapolated from the standard curve (Onyesife et al., 2014). All the experiments were done in triplicates.

\section{Determination of macro and micro-minerals}

The macro-minerals (Calcium, Magnesium, Potassium, Sodium and Phosphorus) and micro-minerals (Iron, Zinc, Aluminium, Manganese and Copper) were determined using the Inductively Coupled Plasma-Optical Emission Spectrometer (ICP-OES) (Bvenura and Afolayan, 2012). All analysis was carried out in triplicates. The phytonutrient, vitamins, macro and micro element contents were expressed as $\mathrm{mg} / 100 \mathrm{~g}$.

\section{Data analysis}

Data were expressed as mean \pm standard deviation. The data was calculated using Graph Pad Prism 4.0V for Windows (Graph Pad Software, San Diego, CA, USA).

\section{Results}

The proximate constituents of B. abyssinica that were tested include; moisture, ash, crude fibre, carbohydrate, protein and lipids. Out of these, crude carbohydrate was the highest proximate factor. There were relatively similar quantities of moisture, ash, crude fibre and crude protein content in this species. The crude lipids had the lowest concentration (Table 1). 
Table 1: Proximate composition (\%) of B. abyssinica A. Rich.

\begin{tabular}{cc}
\hline Parameters & \% Dry matter \\
\hline Moisture content & $8.81 \pm 0.4$ \\
Ash content & $8 \pm 0.61$ \\
Crude fibre & $8.85 \pm 0.02$ \\
Crude carbohydrate & $74.83 \pm 0.64$ \\
Crude protein & $7.68 \pm 0.22$ \\
Crude fat & $0.64 \pm 0.01$ \\
\hline
\end{tabular}

Data expressed as mean \pm SD for triplicate determinations.

The estimated energy values obtainable from crude protein, carbohydrate, lipid content are represented in Table 2 with total energy due to carbohydrate and lipid being the highest and lowest, respectively. The plant showed higher levels of Vitamin E than Vitamin A and C which showed similar levels (Table 3). The levels of oxalate and phytic acids were 2 fold higher than alkaloids, flavonoids and saponins. The phenols and tannins were in trace amounts (Table 3).

Table 2: Calculated energy values as contributed by protein, fat and carbohydrate in B. abyssinica A. Rich.

\begin{tabular}{cc}
\hline Parameter & Value \\
\hline Total energy $(\mathrm{kJ} / 100 \mathrm{~g})$ & $1426.23 \pm 10.82$ \\
PEP $(\%)$ & $9.15 \pm 0.27$ \\
PEC $(\%)$ & $89.19 \pm 0.27$ \\
PEF $(\%)$ & $1.66 \pm 0.01$ \\
UEDP $(\%)$ & $0.39 \pm 0.01$ \\
\hline
\end{tabular}

PEP\%, PEC\%, PEF\% and UEDP\% refers to percentage proportion of total energy due to protein, carbohydrate, fat and utilizable energy due to protein, respectively. Data expressed as mean \pm SD for triplicate determinations.

Table 3: Phytonutrient and vitamin content (mg/100g) of B. abyssinica A. Rich.

\begin{tabular}{cc}
\hline Parameters & Composition $(\mathbf{m g} / \mathbf{1 0 0 g})$ \\
\hline Phenols & $7.90 \pm 1.62$ \\
Tannins & $2.41 \pm 0.30$ \\
Alkaloids & $15.61 \pm 4.55$ \\
Flavanoids & $14.57 \pm 0.72$ \\
Saponins & $11.23 \pm 2.20$ \\
Phytic acid & $30.94 \pm 6.70$ \\
Oxalate & $39.52 \pm 2.07$ \\
Vitamins A & $12 \pm 1.09$ \\
Vitamin C & $12.33 \pm 1.15$ \\
Vitamin E & $22.05 \pm 4.11$
\end{tabular}

Data expressed as mean \pm SD for triplicate determinations.

The macro-minerals that were tested included; sodium, calcium, potassium, magnesium and phosphorus. Of these, potassium had the highest concentration in the plant. This was followed by calcium, magnesium, sodium and phosphorous, respectively. The micro-minerals that were evaluated included; iron, aluminium, zinc, manganese and copper. Among these minerals, iron had the highest concentration in the plant, followed by aluminium, manganese, zinc and copper, respectively (Table 4). 
Table 4: Macro and micro element composition (mg/100g) of B. abyssinica A. Rich.

\begin{tabular}{cc}
\hline Mineral elements & Composition $(\mathbf{m g} / \mathbf{1 0 0 g})$ \\
\hline Nitrogen & $1228.36 \pm 35.72$ \\
Phosphorus & $218.39 \pm 0.005$ \\
Calcium & $1872.21 \pm 52.52$ \\
Magnesium & $310.44 \pm 8.94$ \\
Potassium & $2485 \pm 98.29$ \\
Sodium & $265.13 \pm 13.93$ \\
Iron & $290.85 \pm 39.99$ \\
Zinc & $5.77 \pm 0.06$ \\
Aluminum & $219.24 \pm 14.95$ \\
Manganese & $10.71 \pm 1.19$ \\
Copper & $0.934 \pm 0.06$
\end{tabular}

Data expressed as mean \pm SD for triplicate determinations.

\section{Discussion}

In the present study, the proximate analysis revealed that the carbohydrate content had the highest concentration followed by crude fibre, moisture, ash, crude protein and then crude fat (Table 1). Carbohydrates provide readily accessible fuel for physical performance and regulate nerve tissue. The presence of crude fibre is an indicator of the presence of a proportion of cellulose, hemicellulose and lignin (Igwe and Okwu, 2013). Dietary fibre decreases the absorption of cholesterol from the gut, delays the digestion and conversion of starch to simple sugars. Therefore, it lowers the serum cholesterol, the risk of coronary heart disease, hypertension, constipation, diabetes, colorectal cancer and breast cancer (Igwe and Okwu, 2013). Fibers are necessary for digestion and for effective elimination of wastes. Thus, this medicinal plant can be considered as a valuable source of dietary fiber in human nutrition (Igwe and Okwu, 2013).

Moisture content is important to a number of biochemical reactions, physiological changes and control of body temperature (Igwe and Okwu, 2013). Ash content is a reflection of the mineral contents preserved in the plants. Minerals are essential for the proper functioning of tissues and act as second messengers in some biochemical cascade mechanisms (Antia et al., 2006).

Protein is essential in human system because it functions in the growth, movement and body defense system. Proteins serve as enzymatic catalyst and mediate metabolic and energy regulation (Antia et al., 2006). The lowest parameter noted was crude fat content (Table 1). Lipids (fats) are major structural elements of biological membranes and in transportation of proteins and vitamins. Lipids in combination with certain proteins (aproproteins) mediate a number of enzyme activities. Lipids also play significant role in the body metabolism as high energy yielding elements and wound healing processes (Igwe and Okwu, 2013).

Percentage of proportion of total energy due to carbohydrate (PEC \%) had the highest value, followed by percentage of proportion of total energy due to protein (PEP\%) and then percentage of proportion of total energy due to fat (PEF\%) (Table 2). The total energy was $1,426.23 \mathrm{~kJ} / 100 \mathrm{~g}$ while UEDP\% was $0.39 \%$ (Table 2). These energy values for $\mathrm{PEP} \%, \mathrm{PEF} \%$ and UEDP\% are below the daily energy requirement for an adult and infant (depending on physiological state) as reported by Adeyeye (2014). The PEC\% of $89.2 \%$ is above the recommended daily energy minimum requirements (45-65\%) for human indicating that this plant is valuable source of energy. Energy is important for general health and performance of the body (Adeyeye, 2014).

Phytochemical results showed that alkaloids had the highest concentration followed by flavonoids, saponins, phenols and tannins, respectively (Table 3). Alkaloids mediate important pharmacological activities including; analgesic, reducing blood pressure, killing tumour cells, stimulating circulation and respiration and anti-diabetic (Kam and Liew, 2002).

Flavonoids another constituent of $B$. abyssinica, are hydroxylated phenolic substances occurring ubiquitously in plants. Flavonoids possess a wide range of biological activities including; antimicrobial, anti-inflammatory, analgesic, antiallergic, anticancer, antioxidant and antidiabetic properties (Hodek et al., 2002). The plant revealed to contain saponins. Saponins have anti-inflammatory, blood anticoagulatory and anti-hemolytic activities (Hodek et al., 2002). 
Phenols and tannins were lowest in concentration (Table 3). The phenolic compounds are most ubiquitous groups of plant metabolites acting as primary antioxidants (Han et al., 2007). They possess other biological properties such as antiapoptosis, anti-aging, anti-carcinogen, anti-inflammation, anti-atherosclerosis and cardiovascular protection. Tannins have anti-inflammatory, antimicrobial and antidiabetic properties (Han et al., 2007).

Phytonutrient analysis also revealed high concentrations of phytic acid and oxalate (Table 3 ). Though these have been regarded as anti-nutrients, they possess great medicinal value (Ndidi et al., 2014). Phytic acid posseses inflammatory properties and also inhibit platelet aggregation. Phytic acid acts as antioxidant agent, decreases insulin resistance hence acts as anti-diabetic agent (Omoruyi et al., 2013). Oxalates are known to have detrimental effects in human body. Of importance, the oxalates render other minerals such as calcium unavailable for normal physiological and biochemical functions (Omoruyi et al., 2013). Nevertheless, cooking properly before consumption significantly reduces its detrimental effects (Akwaowo et al., 2000).

From the vitamin analysis, Vitamin $\mathrm{E}$ had the highest concentration while Vitamin A and C had similar concentrations (Table 3). Vitamin $\mathrm{E}$ is the most effective, fat-soluble antioxidant known to occur in the human body. It maintains the integrity of the body's intracellular membranes and provides a defense line against tissue damage caused by oxidation (Ulatowski and Manor, 2013). Vitamin C plays significant functions in the body including; wound healing, activation of enzymes and hormones, antioxidant and strengthening immune system (Iqbal et al., 2004). Vitamin A plays important role in vision, bone growth, reproduction, cell division and differentiation (Martini et al., 2010). These vitamins maintain proper health status of the body. Vitamin A, C and E contents of the plant are sufficient to meet the RDA in human body whose values are 0.3-0.9 mg/day, 30-60 mg/day and 70-300 mg/day in children and adult, respectively (NHMRC, 2005).

The macro minerals that were tested for include; sodium, calcium, potassium, magnesium and phosphorus. Out of these, potassium had the highest concentration in the plant. This was followed by calcium, magnesium, sodium and phosphorous, respectively (Table 4). Potassium is the main intracellular cation in the human body required for vital cellular processes. It is involved in regulating acid-base balance, blood pressure, cell membrane function and basic cellular enzymatic reaction (Chatterjee et al., 2011). The potassium content $(2,485 \mathrm{mg} / 100 \mathrm{~g}$ ) is within the RDA of 2,400-3,800 $\mathrm{mg} /$ day in children and adults, respectively, hence the species is a good source of the mineral (NHMRC, 2005).

Calcium is a mineral needed for optimal bone health and physiological functioning. Calcium acts as a vital second messenger in blood coagulation, hormone secretion action, muscle contraction and nerve function (Pravina et al., 2013). This plant can act as a source of calcium. It contains calcium content $(1,872.2 \mathrm{mg} / 100 \mathrm{~g})$ which is within the RDA of 500 $1,300 \mathrm{mg} /$ day in children and adults, respectively (FAO, 2001).

The plant provides magnesium content $(310.4 \mathrm{mg} / 100 \mathrm{~g})$ which is below the RDA of $450 \mathrm{mg} / \mathrm{day}$ in human (Abrams et al., 1997). Magnesium acts as a cofactor to several enzymes (like kinases) which participate in energy and protein production processes. It's also vital in strengthening cell membrane structure and modulates glucose transport across cell membranes (Jahnen-Dechent and Ketteler, 2012).

The plant contains sodium content $(265.1 \mathrm{mg} / 100 \mathrm{~g})$ which is below the RDA of 460-920 mg/day in children and adults, respectively (NHMRC, 2005). However, its trace level is still important. Sodium is the principal cation in extracellular fluids. It maintenances the osmotic pressure of the body fluids and preserves normal function of the nervous and muscle (Constantin et al., 2011). The plant provides phosphorus (218.4 mg/100g) which is within the RDA of 200$1,000 \mathrm{mg} /$ day in children and adults, respectively (FNB, 1997). Phosphorus is located in every cell of the body and functions as a constituent of bones, teeth, phosphorylated metabolic intermediates and nucleic acids. It is involved in synthesis of phospholipids and phosphor-proteins (Constantin et al., 2011).

The micro minerals that were evaluated for include; iron, aluminium, zinc, manganese and copper. Among these minerals, iron had the highest concentration in the plant, followed by aluminium, manganese, zinc and copper, respectively (Table 4). The species contains iron content $(290.9 \mathrm{mg} / 100 \mathrm{~g})$ which is above the RDA of 9-15 mg/day in children and adults, respectively (NHMRC, 2005). Iron is an important element; it helps in transport of oxygen, electron transport and blood formation. Iron is crucial in energy production, neurotransmitter synthesis and maintaining a stable immune system (Linder, 2013).

The second highest micro mineral in the plant was aluminium. The presence of aluminium is a cause for concern, taking into account that this micro mineral is toxic when consumed in large quantities (Watanabe and Osaki, 2002). The species provides manganese content of $10.7 \mathrm{mg} / 100 \mathrm{~g}$. This is slightly above the RDA of $2-5 \mathrm{mg} / \mathrm{day}$ in children and adults (NNSA, 1998). Manganese acts as a cofactor of several enzymes involved in metabolic processes necessary for the skeletal development, reproductive function and growth. This element is also involved in urea formation, metabolism of amino acids, cholesterol and carbohydrates (Zablocka-Slowinska and Grajeta, 2012).

B. abyssinica provides zinc content $(5.77 \mathrm{mg} / 100 \mathrm{~g})$ which is within the RDA of $4-14 \mathrm{mg} / \mathrm{day}$ in children and adults, respectively (NHMRC, 2005). Zinc is a critical micronutrient required for structural and functional integrity of biological membranes, maintaining homeostasis, regulation of insulin production, regulation of glucose utilization by muscles and fat cells and detoxification of free radicals (Myers et al., 2012). 
The copper content $(0.93 \mathrm{mg} / 100 \mathrm{~g})$ was also within the RDA of $0.7-1.1 \mathrm{mg} /$ day in children and adults, respectively (NHMRC, 2005). Copper is a constituent of key enzymes like cytochrome $c$ oxidase, amine oxidase, catalase, peroxidase, ascorbic acid oxidase, among others, and plays role in iron absorption. It is an essential micronutrient for bone development, pigmentation, hair growth, reproductive system, haematologic and neurologic systems (Tan et al., 2006).

The presence of these proximate, phytonutrients, macro and micro elements indicates that this plant is a good source of the nutrients hence, it can be key in nutritional supplementation. These also accounts for the pharmacological use of $B$. abyssinica in management of diabetes mellitus and complications associated with the disease such as wound healing.

Declaration of Interest: The authors have no conflicting interest.

Acknowledgment: This research was supported by grants from Govan Mbeki Research and Development Centre, University of Fort Hare, South Africa.

\section{References}

1. A.O.A.C (2005). International Official Methods of Analysis ( $18^{\text {th }}$ edition). Association of Analytical Chemists, Washington DC, USA.

2. Abrams, S.A., Grusak, M.A., Stuff, J. and O'Brien, K.O. (1997). Calcium and magnesium balance in 9-14 year old children. American Journal of Clinical Nutrition. 66: 1172-1177.

3. Adeyeye, E.I. (2014). Proximate, minerals and amino acids composition of Acanthurus monronviae and Lutjanus goreensis fish muscle. BMR Biotechnology. 1(1): 1-21.

4. Akwaowo, E.U., Ndon, B.A. and Etuk, E.U. (2000). Minerals and antinutrients in fluted pumpkin (Telfaria occidentalis Hook. F.). Journal of Food Chemistry. 70: 235-240.

5. Antia, B.S., Akpan, E.J., Okon, P.A. and Umoren, I.U. (2006). Nutritive and anti-nutritive evaluation of sweet potatoes (Ipomoea batatas) leaves. Pakistan Journal of Nutrition. 5: 166-168.

6. Bezabih, M., Motlhagodi, S. and Abegaz, B.M. (1997). Phytochemistry. 46: 1063-1067.

7. Bringmann, G., Menche, D., Brun, R., Msuta, T. and Abegaz, B. (2002). Bulbine-knipholone, a new, axially chiral phenylanthraquinone from Bulbine abyssinica (Asphodelaceae): isolation, structural elucidation, synthesis, and antiplasmodial activity. European Journal of Organic Chemistry. 6: 1107-1111.

8. Bvenura, C. and Afolayan, A.J. (2012). Heavy metal contamination of vegetables cultivated in home gardens in the Eastern Cape. South African Journal of Science. 108 (9-10): 1-6.

9. Chatterjee, R., Yeh, H., Edelman, D. and Brancati, F. (2011). Potassium and risk of Type 2 diabetes. Expert Review of Endocrinology and Metabolism. 6(5): 665-672.

10. Constantin, M. and Alexandru, I. (2011). The role of sodium in the body. Balneo. 2 (1): 70-74.

11. Food and Agricultural Organization of the United Nations (FAO) (2001). World Health Organization. Human Vitamin and Mineral requirements. Report of a Joint FAO: WHO expert consultation, Bangkok, Thailand. Rome.

12. Food and Nutrition Board (FNB) (1997). Dietary reference intakes for calcium, phosphorus, magnesium, vitamin D and fluoride. Institute of Medicine, Washington, DC, National Academy Press, USA.

13. Han, X., Shen, T. and Lou, H. (2007). Dietry polyphenols and their biological significance. International Journal of Molecular Sciences. 1: 950-988.

14. Hodek, P., Trefil, P. and Stiborova, M. (2002). Flavonoids-potent and versatile biologically active compounds interacting with cytochrome P450. Chemico-Biological Interactions. 139: 1-21.

15. Igwe, O.U. and Okwu, D.E. (2013). Investigation of the chemical composition of Brachystegia eurycoma harms plant parts used in herbal medicine, International Research Journal of Pharmaceutical and Applied Sciences. 3 (6): 51-55.

16. Iqbal, K., Khan, A. and Khattak, M.A.K. (2004). Biological significance of Ascorbic acid (Vitamin C) in human health: A Review. Pakistan Journal of Nutrition. 3(1): 5-13.

17. Jahnen-Dechent, W. and Ketteler, M. (2012). Magnesium basics. CKJ. 5(1): 3-14.

18. Kam, P.C. and Liew, A. (2002). Traditional Chinese herbal medicine and anaesthesia. Anaesthesia. 57: 1083-1089.

19. Linder, M.C. (2013). Mobilization of stored iron in mammals: A Review. Nutrients. 5(10): 4022-4050.

20. Marcel, A. and Bievenu, M.J. (2012). Proximate, Mineral and Phytochemical Analysis of the Leaves of $H$. myriantha and Urera trinervis. Pak J Biol Sci. 15: 536-541.

21. Martini, L.A., Catania, A.S and Ferreira, S.R. (2010). Role of vitamins and minerals in prevention and management of type 2 diabetes mellitus. Nutrition Research Reviews. 68 (6): 341-354.

22. Moses, D.O. and Yemisi, A.E. (2010). Microbiology and Proximate Composition of 'Ogiri', A Pastry produced from different melon seeds. New York Science Journal. 3(4): 18-27. 
23. Myers, S.A., Nield, A. and Myers, M. (2012). Zinc transporters, mechanisms of action and therapeutic utility: Implications for Type 2 diabetes mellitus. Journal of Nutrition and Metabolism. Article ID 173712, 13 pages,doi:10.1155/2012/173712.

24. Naik, V.V., Patil, N.S., Aparadh, V.T. and Karadge, B.A. (2014). Methodology in determination of oxalic acid in plant tissue: a comparative approach. Journal of Global Trends in Pharmaceutical Sciences. 5(2): 1662-1672.

25. National Nutrition Surveys of Australia (NNSA) (1998). Ministry of Health. NZ food: NZ People. Key results of the 1997 National Nutrition Survey. Wellington: Australia.

26. Ndidi, U.S., Ndidi, C.U., Olagunju, A., Muhammad, A., Billy, F.G. and Okpe, O. (2014). Proximate, anti-nutrients and mineral composition of raw and processed (boiled and roasted) Sphenostylis stenocarpa seeds from Southern Kaduna, Northwest Nigeria. Nutrition. Article ID 280837, 9 pages, doi:10.1155/2014/280837.

27. NHMRC (2005). Nutrient Reference Values for Australia and New Zealand including Recommended Dietary Intakes. Department of Health and Ageing, Australian Government, Australia.

28. Omoruyi, F.O., Budiaman, A., Eng, Y., Olumese, F.E., Hoesel, J.L., Ejilemele, A. and Okorodudu, O.A. (2013). The potential benefits and adverse effects of Phytic acid supplement in streptozotocin-induced diabetic rats. Advances in Pharmacological Sciences. Article ID 172494; doi:10.1155/2013/172494.

29. Onyesife, C.O., Ogugua, V.N. and Anaduaka, E.G. (2014). Investigation of some important phytochemicals, vitamins and mineral constituents of ethanol leaves extract of Piper nigrum. Annals of Biological Research. 5 (6): 20-25.

30. Oyedemi, S.O., Bradley, G. and Afolayan, A.J. (2009). Ethnobotanical survey of medicinal plants used for the management of diabetes mellitus in the Nkonkobe municipality of South Africa. Journal of Medicinal Plants Research 3(12): 1040-1044.

31. Pooley, E. (1998). A field guide to wild flowers of KwaZulu-Natal and the Eastern Region. Natal Flora Trust Publications, Durban.

32. Pravina, P., Sayaji, D. and Avinash, M. (2013). Calcium and its role in human body. International Journal in Pharmaceutical and Biomedical Sciences. 4 (2): 659-668.

33. Tahirovic, A., Janicijevic, A.C., Basic, N., Klepo, L. and Subasic, M. (2012). Determination of vitamin C in flowers of some Bosnian Crataegus L. Species. Faculty of Forestry, University of Sarajevo. 2: 1-12.

34. Tan, J.C., Burns, D.L. and Jones, H.R. (2006). Severe ataxia, myelopathy and peripheral neuropathy due to acquired copper deficiency in a patient with history of gastrectomy. Journal of Parenteral and Enteral Nutrition. 30: 446-450.

35. Ulatowski, L. and Manor, D. (2013). Vitamin E trafficking in neurologic health and disease. Annual Review of Nutrition. 33:87-103.

36. Wanjohi, J.M, Yenesew, A., Midiwo, J.O., Heydenreich, M., Peter, M.G., Dreyer, M., Reichert, M. and Bringmann, G. (2005). Three dimeric anthracene derivatives from the fruits of Bulbine abyssinica. Tetrahedron. 61: 2667-2674.

37. Watanabe, T. and Osaki, M. (2002). Mechanisms of adaptation to high aluminium condition in native plant species growing in acid soils: A Review. Communication in Soil Science and Plant Analysis. 33: 1247-1260.

38. Wintola, O.A. and Afolayan, A.J. (2011). Phytochemical constituents and antioxidant activities of the whole leaf extract of Aloe ferox Mill. Pharmacognosy Magazine. 7(28): 325-333.

39. Zablocka-Slowinska, K. and Grajeta, H. (2012). The role of manganese in etiopathogenesis and prevention of selected diseases. Postepy Higieny Medycyny Doswiadczalnej. 66: 549-553. 